\section{Brugada-Like ECG Pattern in a Patient with Isolated Right Ventricular Infarction}

\author{
Holger Eggebrecht, Heinrich Wieneke, Raimund Erbel ${ }^{1}$
}

'Department of Cardiology, West-German Heart Center Essen, University of Duisburg-Essen, Essen, Germany.

Herz 2009;34:327 DOI $10.1007 /$ s00059-009-3241-6

\begin{abstract}
A 55-year-old female patient collapsed at home with sudden cardiac death. Upon arrival of the emergency physician, the patient was defibrillated for ventricular fibrillation (VF). After successful mechanical resuscitation, the patient was transferred to our intensive care unit requiring high-dose vasopressor support. The electrocardiogram (ECG) at presentation showed atrial fibrillation with right bundle branch block and cove-type ST segment elevation in leads $\mathrm{V}_{1}$ and $\mathrm{V}_{2}$, ECG abnormalities suggestive of Brugada syndrome (Figure 1). Transthoracic echocardiography showed left ventricular hypertrophy and preserved systolic left ventricular function without significant wall motion abnormalities. Right ventricular function was, however, markedly reduced. Myoglobin at presentation was $1,287 \mathrm{mg} / \mathrm{l}$ with a creatine kinase of $134 \mathrm{U} / \mathrm{l}$ and a troponin I of $0.02 \mathrm{ng} / \mathrm{ml}$.
\end{abstract}

Because of the conspicuous ECG changes, Brugada syndrome was initially suspected and coronary angiography was delayed in order to stabilize the patient hemodynamically. During the next hours, the patient developed recurrent episodes of VF, which were refractory to amiodarone and could finally be prevented by transjugular venous pacing at 90 beats per minute. Laboratory analysis exhibited a significant rise in cardiac markers and the patient underwent coronary angiography. Coronary angiography revealed proximal thrombotic occlusion of a small nondominant right coronary artery (Figure 2a), which could be successfully recanalized (Figure $2 b)$.

Isolated right ventricular infarction is an extremely rare event. It has been associated with unusual ECG appearances which may be misinterpreted or even missed if not suspected. Ischemia of the right ventricular free wall to the outflow tract may cause ST segment elevations in leads $\mathrm{V}_{1}-\mathrm{V}_{3}$ similar to Brugada syndrome, as in the present case. Similar Brugada-like ECG pattern may also occur in hypothermic patients or patients that have undergone mechanical resuscitation. In the literature, there have been several case reports highlighting that Brugada syndrome can be mistaken for acute myocardial infarction. This case illustrates that the reverse may also occur.

\section{Address for Correspondence}

Dr. Holger Eggebrecht

Department of Cardiology

University of Duisburg-Essen

Hufelandstraße 55

45122 Essen

Germany

Phone $(+49 / 201) 723-3363$, Fax -5931

e-mail: holger.eggebrecht@uk-essen.de
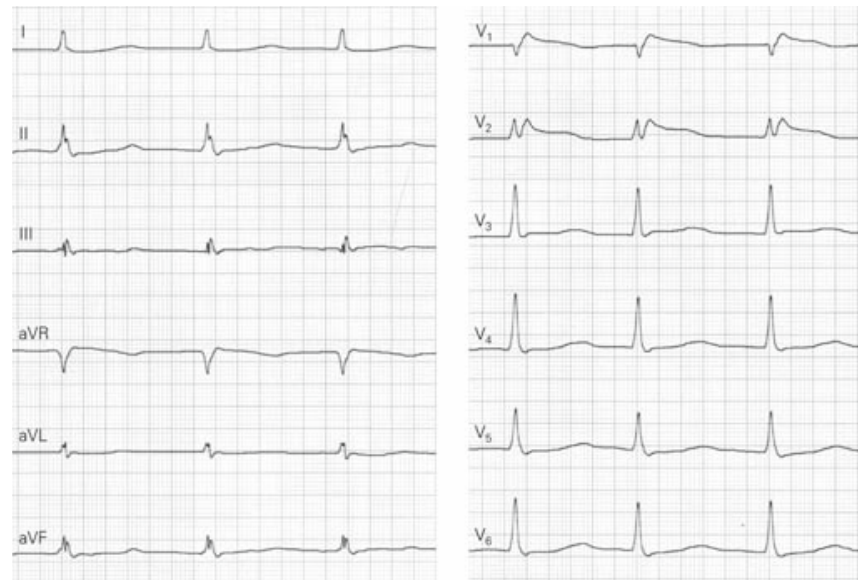

Figure 1. Twelve-lead ECG showing right bundle branch block and cove-type ST segment elevation in leads $V_{1}$ and $V_{2}$, ECG abnormalities suggestive of Brugada syndrome.
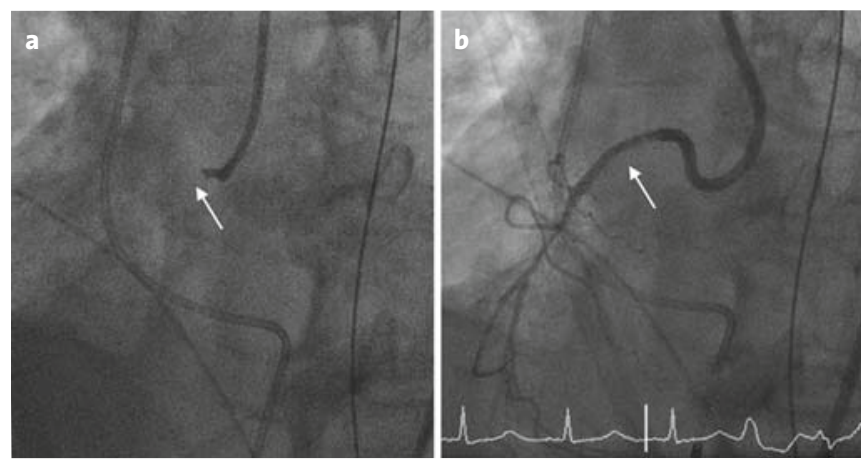

Figures $\mathbf{2 a}$ and $\mathbf{2 b}$. a) Preinterventional coronary angiogram showing proximal thrombotic occlusion of a small nondominant right coronary artery (RCA, arrow). b) Angiographic result after recanalization and balloon angioplasty of the RCA (arrow). 